\title{
An Analysis of Tenor Aria Singing Style in Tsiolkovsky's Opera Works--Taking Youth, Where Are You as an Example
}

\author{
Liu Songzhang \\ Heyuan Polytechnic, Gungdong, China, 517000
}

Keywords: Opera; tenor; Aria

Abstract: This paper makes a detailed music analysis of Lewinsky's aria Youth, Where Are You in Tsiolkovsky's opera Eugene Onegin, so that the singer can accurately grasp the composer's intention in the interpretation and understanding of his works.

Peter Chalice Tchaikovsky is a great Russian Romantic composer and representative figure of Russian national music school. He is known as a great Russian music master. His style directly and indirectly influenced many later generations. From 1877 to 1878, Tchaikovsky wrote the opera Eugene Onegin according to Munchkin's poetry style. It opens up a new and broad prospect for the development of realist tradition in Russian musical drama. In this opera, Tsiolkovsky's most important aesthetic principles in opera creation have been fully and in many ways embodied. This opera fully expresses the thoughts and feelings of contemporary Russian people, and expresses the inner feelings of the characters thoroughly. Youth, where are you is a famous aria sung by Kandinsky before the duel in the second act of the opera.

\section{The Outline of the Opera Story and the Musical Style of the Aria}

The three acts and seven operas, Eugenie Onegin, are summarized as follows: the kind, simple and sentimental Tajikistan fell in love with Onegin at first sight, the noble young man who came to visit her family, and wrote to Onegin to tell him her love for him. Onegin, who was deeply tired of the emptiness of the noble life at that time, refused her love. Instead, he courted Tijuana's sister, Orca, at the dance, which angered Ora's lover, his friend and young poet, Kandinsky, resulting in a duel between them. As a result, Kandinsky was killed in the duel. Six years later, Onegin met Tajikistan, who had married Duke Geminate, at a social dance. The dignified and noble Tajikistan awakened Onegin's deep love. He confessed to Tajikistan, and Tajikistan eventually rejected Onegin." Youth, Where Are You" is the aria sung by Kandinsky before the duel between Kandinsky and Onegin in the second act of the opera. It has a strong tragic atmosphere. The musical language is characterized by beautiful melody, simple and sincere moving, which fully reflects Lewinsky's complex mood and real feelings at that time.

\section{Music Analysis}

This aria is composed of a prelude plus a mono-trilogy with an introduction and a finale. The 
whole aria is in E minor. Before that, Lewinsky's melody had used E major, and in the end, the aria was changed into a minor with the same name. On the one hand, on the basis of the unification of modes, Kandinsky highlighted the sadness and eroticism of the minor. On the other hand, E minor was often used in Russian urban romance at that time. Here, Lewinsky's national temperament was emphasized. Before the beginning of the aria, there was a long Prelude played by brass pipe and cello, which was very heavy and had funeral color. It seemed to be a prediction of Lewinsky's tragic fate. Next came the theme of the hero's fate. It is first introduced by strings, accompanied by clarinet accompaniment, the tragic fate of the characters is very profound. As shown in figure 1:

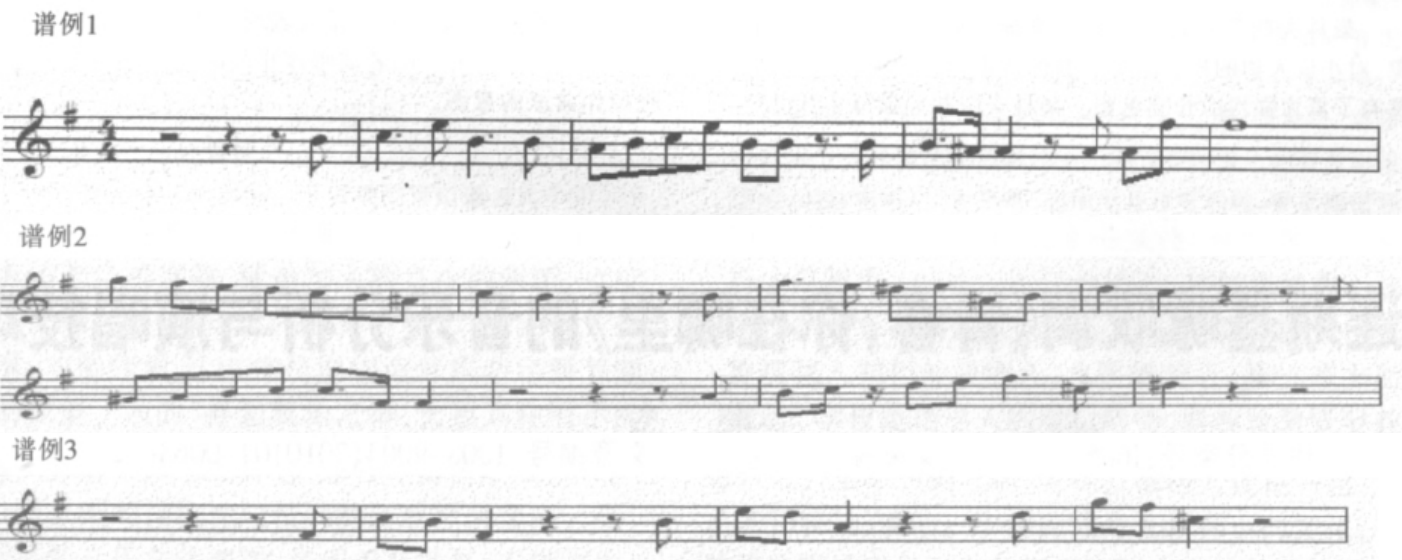

Figure 1. Music Analysis

With the accompaniment of simple chords, Lewinsky's confusion and helplessness are depicted by introducing emotional questions which are expressive in speech and full of singing. Next came part A of the aria, with basic themes that had already been heard in the prelude. At the same time, Tchaikovsky often uses the melodic form of expression of sadness - the first-level downward and downward form, the syncopated rhythm of the band, the lining of the upward melody, which brings excitement and uneasiness to the music. The Orchestra mainly consists of strings and woodwind, which highlights the loneliness of Lewinsky's heart at this time.

The composer of part B of the aria wrote a narrative melody, continuing the "dialogue" between part A vocal part and the band, creating a sense of continuous melody. The speed is slightly faster, the tonality is unstable ( $\mathrm{G}$ major to B major and $\mathrm{E}$ minor), and the harmonic transformation is more frequent, showing that Kandinsky is emotionally agitated and full of bad feelings. The beautiful phrases of the cello's downward melody lead to a powerful reproduction. As shown in Spectrum 2.

In the first paragraph of the basic theme, there is a melody that has never appeared before (weak rise section). Because of his missing his lover, the mood here becomes intense and exciting, and the development of the whole melody is more intense. By using the method of theme core development, the climax of the music is driven by the continuous improvement of the theme, and the high-pitched area, the intensity and the relaxed melody rhythm are all in common. Under the same function, it is realized in the expression processing of the comprehensive review of the central tonality implied by harmony. Express the cry of Lewinsky's heart. The final ending corresponds to the lyrics and music materials of the introduction, but harmony embodies a kind of ending style of "only asking but not answering". Thus, Lewinsky's fate ended sadly. As shown in Spectrum 3.

\section{Analysis of Problems in Singing}

The last part is the most brilliant and powerful part of the whole aria, which requires full emotions and progressive layers. At the same time, it also needs to maintain a good voice position 
and state. Only when the treble is brilliant, can it almost achieve the singing requirements of this part perfectly. But when many singers sing this part, they often have many problems of one kind or another. As shown in Table 1:

Table 1 Analysis of Problems in Singing

\begin{tabular}{|c|c|}
\hline $\begin{array}{c}\text { the problem of } \\
\text { endurance }\end{array}$ & $\begin{array}{c}\text { Because there is no room for the interlude to give the singer a } \\
\text { rest, it is difficult to sing it completely without a solid } \\
\text { foundation. }\end{array}$ \\
\hline $\begin{array}{c}\text { the problem of } \\
\text { vocal skills }\end{array}$ & $\begin{array}{c}\text { In this section, there are a large number of voice change areas, } \\
\text { such as Sheng F, G, etc. Without good closing ability and } \\
\text { technology, it is impossible to achieve the unification of the } \\
\text { voice area, nor can it give people aesthetic enjoyment in the } \\
\text { sense of hearing. }\end{array}$ \\
\hline emotional input & $\begin{array}{c}\text { This section is relatively high in the melody area. In our vocal } \\
\text { jargon, it is a little "hanging". With the influence of harmony } \\
\text { and sound effects, it is easy to "support and stress" singing. It is } \\
\text { often more or more emotionally, which will inevitably affect } \\
\text { the final treble. }\end{array}$ \\
\hline
\end{tabular}

The importance of breathing is clearly indicated by many vocal masters. "Singing is breathing," said Elizabeth Schumann, the famous Australian soprano Melba. "To sing perfectly, it's more important to breathe correctly than to have a beautiful voice. The art of breathing is the most important thing for a singer. Pagoda Glottis once said, "He who knows how to breathe and pronounce knows how to sing." This shows the importance of breathing. Because the aria has the characteristics of tragic lyricism, the use of breathing is particularly important. We should pay great attention to the fluidity of breathing, which is embodied in the moderation of the expansion of diaphragm and contraction of abdominal muscles. Only moderation can make sound flow. If not moderation, it will destroy the coherence of sound and make the music tasteless.

The image of Kandinsky in literature is positive on the surface.Appearance, but actually contains derogatory elements, representing some of the status duo, conservative aristocratic youth. But in the opera, Tchaikovsky gives more positive colors to this character, more praises his persistence in love and regrets for his tragic fate, thus making Lewinsky's musical image the most outstanding part of the opera.

The contraction of abdominal muscles mentioned in the book "The Art of Singing" is of great help to strengthen breathing. Now let's see how five tenors deal with these problems. Caruso added a lot of crying in this passage, and appropriately, especially the last long one, hoarseness and exhaustion, tearing people's hearts and lungs, fully expressing Cavalier's excitement, despair and pain at this time, from the emotional point of view, it seems very devoted, fully integrated into the role. Caruso was basically faithful to the composer's original intention and tried to sing in accordance with the requirements of the spectrum, such as the music marks above grit. (slowing down), "e mullion" at the beginning, the "cementation UN Pocono con Mani (more laboriously and freely)" and each delay mark and accent mark at the final climax, etc. He was clear and clear.

In terms of sound, Caruso is the first tenor singer in history to adopt the closed singing method. There is no fault in using the natural closed vowel, especially when singing to the "a" vowel and "e" vowel entering the voice changing area, "a" has a slightly "o" feeling, and "e" has a slightly similar feeling to the "o" sound in French, which makes the voice easy to enter the channel and appears more rounded. More unified, but also conducive to a better open tenor. In the phrase "e non ho Amado Mai Cantor la vita", Caruso uses it as an upward scale phrase to gradually adjust the position and state of each word and sound, to turn off $G$ as a transition, and to open it twice on the 
top A, so that the treble sounds are particularly brilliant and penetrating, and with the help of music, emotion and the band, Leoncavallo will be promoted. The inner pain and despair are fully displayed to the audience and the audience.

Geeky inherited Carlo's closing singing method, paying special attention to the deformation of vowels and the support of breath in closing tones, but on the top A, it was not as open as Carlo's, but still kept a closed state, just to increase the flow of breath and promote it. In my opinion, Geeky did not want to destroy the purity of the "o" vowel. In music, Geeky tries to sing the time value required by each phrase to achieve the coherence of music. When he sings the climax part, he does not like Caruso, but uses the sentence breaks between "amateur" and "Mai" to take a deep breath and emphasize the stress of "Mai" more explosively, which is convenient for singing and vividly portraying the image of the characters by means of tone. Then the whole song ended with a cry, which sublimated the mood. I personally appreciate Clair singing in this part. In terms of voice, he does not have obvious closing marks like Caruso and Geeky. He does not shut down mechanically, but mixes falsetto into real voice in advance on the basis of ensuring the purity of vowel pronunciation.

In his previous singing, we can feel that Collin began to use "mixed voice" gradually from the middle tone area, so that the timbre is not only full of rich head resonance, but also appears to be music flow, easy to attract the audience. For this part of the singing, Choleric pays more attention to the fluency of music and emotional fullness, coupled with more open singing and grand voice, enough to express the emotions and personality of music. Parodist's singing strengthens the granularity and tone of his voice, but this will not destroy the smoothness and fluency of his music. He pays more attention to the connection between every sound and every word, and is careful in dealing with every tone in the changing area, including the performance on the top A. He does not burst out the high tone at once, but stabilizes it first and then promotes it. It seems that it is too rational to give people a feeling, but the inherently beautiful tone and stable style still win the audience's favor. Love.

Domingo is one of the most passionate tenors, not to mention the voice, the external performance alone is enough to attract the audience, exaggerated body movements and rich facial expressions, leaving a deep impression on the audience. Domingo's voice is filled with all the feelings from the beginning of this passage, which seems to have some feeling of screaming. Although the tone of the treble is affected by some factors, it is necessary from the perspective of role limitation and emotional requirements.

\section{Conclusion}

Through the analysis of the singing style and singing skills of tenor singers in singing arias, we find that to sing this work well, we need not only profound singing skills, but also rich experience, accurate grasp of characters and emotional treatment, coupled with the "second creation" of the work and personal interpretation of the work, we can fully express this work. Product.

\section{References}

[1] J Hongi. Outline of Opera Aesthetics [M]. Hefty: Inhuman Literature and Art Publishing House, 2003

[2] Chou Deng, Thu Xiang. Selections of Foreign Opera [M]. Shanghai: Shanghai Music Publishing House, 2002

[3] Li Jillian. Singing Analysis of Two Tenor Arias by Leoncavallo in Tosca [J]. Popular Literature and Art (Theory), 2009 (13)

[4] Chou Julianne. An Analysis of the Singing Style of the Aria "Starlight Brilliant"--Taking Domingo, Pavarotti and Wei Song as the model singers [J]. Huang Thong (Journal of Wuhan Conservatory of Music, China), 2007 (04)

[5] Kong Fanning. Viewing Tsiolkovsky's Opera Style from Eugene Onegin [D]. Master's Thesis Collection of Tianjin Conservatory of Music, 2004:21. 